\title{
Electrocardiographic Changes in Patients with Type 2 Diabetes Multicenttic Cross Sectional and Descriptive Study in Dakar
}

\author{
Michel Assane Ndour ${ }^{*}$, Leye Abdoulaye ${ }^{1}$, Fall Biram Codou ${ }^{1}$, Leye Yakham Mohamed ${ }^{1}$, \\ Ndiaye Nafy'1, Diack Ngoné Diaba ${ }^{1}$, Fall Aichetou', Mbaye Alassane ${ }^{2}$, Diao Maboury ${ }^{3}$, \\ Diop Moreira Therese ${ }^{4}$
}

\begin{abstract}
${ }^{1}$ Department of Internal Medicine/Endocrinology, National Pikine Hospital Center, Dakar, Senegal
${ }^{2}$ Department of Cardiology, Center Hospital Aristide le Dantec, Dakar, Senegal

${ }^{3}$ Department of Cardiology, National Hospital Center of Grand Yoff, Dakar, Senegal

${ }^{4}$ Department of Internal Medicine, Center Hospital Aristide le Dantec, Dakar, Senegal, Faculty of Medicine of Cheikh Anta Diop University of Dakar, Dakar, Senegal

Email: *michelassanendour@yahoo.fr, ablayleye@hotmail.com, biramfall86@gmail.com, leyeyakham@yahoo.fr, fyfynami@yahoo.fr, diackngone@gmail.com, aichaa776@yahoo.fr, ambaye@hotmail.com, diaomaboury@hotmail.com, tmoreiradiop@gmail.fr
\end{abstract}

How to cite this paper: Ndour, M.A., Abdoulaye, L., Codou, F.B., Mohamed, L.Y., Nafy, N., Diaba, D.N., Aichetou, F., Alassane, M., Maboury, D. and Therese, D.M. (2017) Electrocardiographic Changes in Patients with Type 2 Diabetes Multicenttic Cross Sectional and Descriptive Study in Dakar. Open Journal of Internal Medicine, 7, 64-73.

https://doi.org/10.4236/ojim.2017.73007

Received: July 14, 2017

Accepted: August 18, 2017

Published: August 21, 2017

Copyright (c) 2017 by authors and Scientific Research Publishing Inc. This work is licensed under the Creative Commons Attribution International License (CC BY 4.0).

http://creativecommons.org/licenses/by/4.0/

cC) (i) Open Access

\begin{abstract}
Introduction: The resting electrocardiogram is generally called upon in the evaluation of cardio-vascular risk in diabetics. Thus we proposed in this work to evaluate electrocardiographic changes in patients with type 2 diabetes. Methods: This was a cross-sectional and descriptive observation that took place from 1 January 2014 to 1 October 2014 in the Internal Medicine/Endocrinology Departments of Pikine National Hospital and Cardiology National Hospital of Grand-Yoff. Results: One hundred (100) patients consisted of 43 male and 57 female diabetics. The sex ration male/female ratio was 0.7 . The average age was 58.3 years. Men were twice as likely to be active as women. Rhythm disorders were noted in $20 \%$ of patients, $13 \%$ of whom were women. Right atrial hypertrophy was found in $11 \%$ of patients and left hypertrophy in both men and women (25\%). Wolf-Parkinson White syndrome was present in $2 \%$ of patients. A complete right bundle block was present in $11 \%$ of patients. Primary repolarization disorders were noted in $17 \%$ of patients and secondary in $18 \%$ of patients, postero-diaphragmatic necrosis in $14 \%$ of patients, real posterior necrosis in $2 \%$ of patients, extensive anterior necrosis in $15 \%$ of patients. The QT interval was lengthened in $21 \%$ of patients including 14 women. Left ventricular hypertrophy was present in $33 \%$ of patients and right ventricular hypertrophy was found in $10 \%$ of patients. The bivariate analysis showed that electrocardiographic abnormalities were more correlated with the association of certain risk factors such as hypertension and dyslipidemia, the feminine
\end{abstract}


gender, but also the poor glycemic balance. On the other hand, physical activity and treatment had a protective effect. Conclusion: The ECG is certainly insufficient for an exhaustive exploration of the heart of the diabetic patient, but still very useful in our conditions of exercise to improve the care of our patients.

\section{Keywords}

Diabetes, ECG, Heart, Dakar, Cardiovascular Disease

\section{Introduction}

Diabetes mellitus is currently a pandemic [1]. It is a formidable metabolic disorder because of its evolution, most often insidious. This leads to a delay in diagnosis and has the consequence of exposing the patients to complications especially cardio-vascular [2]. Resting electrocardiogram is commonly used among the range of complementary examinations for cardiovascular risk evaluation. It allows to highlight a number of abnormalities regardless of the existence of cardiovascular risk factors but also and especially ischaemic heart disease often in silent clinical expression [3]. The ECG poses in our regions a problem of availability and achievement due to lack of means. As a result, diabetic patients lose any benefit from their realization on their care, but also our knowledge of the prevalence of electrocardiographic abnormalities, their distribution and their determinants within this population remain limited. Such knowledge is valuable not only to help to better adapt international practical recommendations to local realities but also to highlight the particularities of our patients compared to those elsewhere and to follow their evolution over time.

In view of these realities, we thought it was necessary to participate at least partially to better understand electrocardiographic abnormalities of people with diabetes in our context, setting down the prevalence and determinants of electrocardiographic changes in patients with type 2 diabetes to the Department of Internal Medecine of the National Hospital of Pikine and Cardiology of Grand Yoff. Moreover, we are not aware of any previous studies on this subject in Senegal.

\section{Patients and Methods}

We made our survey in 2 national hospitals located in the Dakar region: National Hospital of Pikine, Department of Internal Medicine and National Hospital of Grand Yoff, cardiology department. These two centers are references in the context of the care of patients living with diabetes.

This was a cross-sectional and descriptive observation survey. The study was conducted during the period from 1 January 2014 to 1 October 2014. It consisted of all patients with type 2 diabetes cared in hospital. All type 2 diabetic patients 
were included in the study, regardless of gender, age, ethnicity, or religion. The patient was informed of the subject of our study and his consent requested in view of its inclusion in our study. He was also aware of his diabetes status and the complications he would be exposed to. The data were collected in strict respect of medical confidentiality.

All patients were systematically checked up annually as part of the care of their disorders. This check up included a physical examination, fasting blood glucose test, multi-reagent test urine, serum creatinine assay with calculation of creatinine clearance, lipid balance including total cholesterol dosage, HDL cholesterol and triglycerides), a glycated hemoglobin assay (HbA1c), a resting ECG, and an ophthalmologic examination with an eye or retinography background. Our patients were recruited as part of this annual review.

The interrogation and consultation of clinical records of the participants would allow then to gather information on the status, circumstances of diabetes discovery, existing complications and their stages, on-going drug therapy, cardiovascular risk factors, family history. Each patient had a medical record with a complete physical examination, the examination data were summarized into syndromic summary.

The ECG with 12 leads was systematic in all patients; it provided the anomalies found during the interpretation.

The main axes were the rhythm, the regularity, the search for rhythm disorders, the P wave, the PR interval, the QRS complex, the ST segment, the T wave, the QT interval, the overload.

Variants of the normal ECG:

In the elderly individual: often respiratory arrhythmias, arrhythmias with extrasystole type, low voltage (endomyocardial fibrosis), left axial deviation, repolarization disorders were noted.

In obese patients: the decrease of the amplitude of the $\mathrm{R}$ waves in all the branches, the QRS axis can be deviated to the left, the T waves flattened and the fine $\mathrm{Q}$ waves in the positional posterior derivations.

In competition athletes: sinus bradycardia, lengthening of the PR interval (BAV $1^{\text {st }}$ degree) with sometimes aspects of $2^{\text {nd }}$ stage BAV with Wenckebach period.

In black subjects: anomalies of ventricular repolarization, straight precordial derivations +++ .

Other tests were made according to the clinical orientation:

Holter ECG, Echocardiography, Echodoppler of the neck vessels, abdominal echography, brain scan etc.

A questionnaire was submitted to each patient. The data were collected on the basis of a pre-coded, anonymous and self-administered questionnaire. The patient was informed of the subject of our study and his consent requested in view of its inclusion in our study. He was also aware of his diabetes status and the complications he would be exposed to. Data were collected in strict compliance 
with medical confidentiality.

To determine the size of the sample, this formula: $n=(z)^{2} p(1-p) / d^{2}$.

$\mathrm{n}=$ sample size; $\mathrm{z}=$ confidence level according to the normal centered reduced law (for a confidence level of $95 \%, z=1.96$, for a confidence level of $99 \%$, $\mathrm{z}=2.575) ; \mathrm{p}=$ estimated proportion of the population with the characteristic (when unknown, $\mathrm{p}=0.5$ ); $\mathrm{d}=$ tolerated margin of error (for example, the actual proportion is to be $5 \%$ ).

The results were captured and analyzed using electronic questionnaire developed using SPSS 20.0 software. The graphics were made using the Excel module of the 2007 MS Office suite. This software had allowed calculating frequencies, averages and standard deviations. The bivariate analysis was made using the Chi-square tests (Pearson and Yates) for comparisons of proportions. The comparison of the average was carried out using the Student test. The difference was considered to be statistically significant at $<5 \%$. The odds ratio (OR) surrounded by its confidence interval allowed to quantify the strength of the bond. Variables with more than $10 \%$ missing data were not analyzed.

The study population was described using variables studied. This descriptive study was done with the calculation of frequencies for the quantitative variables.

\section{Results}

\subsection{Clinical Profile of Patients}

The 100 patients recruited consisted of 43 patients living with the male-type diabetic and 57 with the female-type diabetic women. The sex ratio was 0.7. The average age of the patients was 58.3 years with a standard deviation of 13.7. The extremes were 30 and 84 years with a median of 60 years. The most represented age group for women was 58 - 68 years (31.5\% of women) and $47-57$ years for men $(27.9 \%)(p=0.043)$. Men were twice as likely to work as women, with a statistically significant difference $(\mathrm{p}<0.05)$.

In our series, 54 patients had pre-existing complications including 33 with non-proliferative diabetic retinopathy. Men were 3 times more likely to be active smokers than women, and the difference was statistically significant $(\mathrm{p}<0.001)$.

HTA was found in $71 \%$ of our patients, more common in women: $57.7 \%$ of women were hypertensive compared to $42.2 \%$ of men. The difference was not statistically significant $(\mathrm{p}=0.095)$. Among the hypertensive known on drugs treatment, the majority were monotherapy, the enzyme inhibitors and calcic inhibitors were the most prescribed in almost $30 \%$ of cases.

The prevalence of dyslipidemia was $34.1 \%$ that is to say 34 individuals. The majority was marked by a high LDL-c level (32\%). A low HDL level was observed in 29 patients (29\%). A higher rate of LDL-cholesterol was found more frequently in women: $17 \%$ compared to $15 \%$ for men; this difference was not statistically significant $(\mathrm{p}=0.4)$.

Hygiene-dietetic measures were required throughout the $100 \%$ treatment. They were the first stage of treatment associated with metformin or another 
non-insulin antidiabetic drug to $74 \%$. The majority of our patients $(80 \%)$ had blood glucose levels above $1.26 \mathrm{~g} / 1$ (7 mmol/l).

The average $\mathrm{HbA} 1 \mathrm{C}$ was $7.9 \%$ with a standard deviation of 1.2. Extremes ranged from $6 \%$ to $12 \%$. Hypertriglyceridemia was more frequent in women: $31 \%$ versus $17 \%$, the difference was statistically significant $(\mathrm{p}<0.001)$. These results are confined to Table 1 .

Table 1. Profile of 100 diabetic patients.

\begin{tabular}{|c|c|c|c|c|}
\hline Variables & $\begin{array}{l}\text { Men } \\
\text { n (\%) }\end{array}$ & $\begin{array}{c}\text { Women } \\
\text { n (\%) }\end{array}$ & $\mathrm{p}$ & $\begin{array}{l}\text { Total } \\
\mathrm{n}(\%)\end{array}$ \\
\hline Number & $43(43 \%)$ & $57(57 \%)$ & 0.08 & 100 \\
\hline Average age & 58.7 & 57.83 & 0.043 & \\
\hline Occupation & $28(65.96 \%)$ & $21(35 \%)$ & $\mathrm{p}<0.05$ & $49(49 \%)$ \\
\hline Smoking & $6(6 \%)$ & $2(2 \%)$ & $\mathrm{p}<0.001$ & $8(8 \%)$ \\
\hline Known median duration of diabetes & $6(0-22)$ & $7(1-4)$ & & $74(74 \%)$ \\
\hline \multicolumn{5}{|l|}{ Hypertension and treatment } \\
\hline HTA & $35(57.7 \%)$ & $24(42.2 \%)$ & $\mathrm{p}=0.095$ & $65(65 \%)$ \\
\hline Systolic blood pressure & $145.6(45.7 \%)$ & $151.3(32.3 \%)$ & 0.34 & $38(38 \%)$ \\
\hline Diastolic blood pressure & $84(15.2 \%)$ & $91(14.3 \%)$ & 0.20 & $14(14 \%)$ \\
\hline Diuretics & $3(1 \%)$ & $4(0.9 \%)$ & & $(10.1 \%)$ \\
\hline ACE inhibitors & $9(3.1 \%)$ & $7(1.6 \%)$ & & $(25.4 \%)$ \\
\hline Calcium inhibitors & $8(2.8 \%)$ & $10(2.4 \%)$ & & $(27.1 \%)$ \\
\hline Central & 0 & $2(0.4 \%)$ & & $(1.6 \%)$ \\
\hline Beta-blockers & $3(1.05 \%)$ & $4(0.9 \%)$ & & $(10.1 \%)$ \\
\hline Bithérapy & $5(1.7 \%)$ & $6(1.4 \%)$ & & $10(16.9 \%)$ \\
\hline \multicolumn{5}{|l|}{ Lipid profile profil lipidique } \\
\hline Hypertryglyceridaemia & $4(1.7 \%)$ & $8(4.5 \%)$ & 0.4 & $12(12 \%)$ \\
\hline Hypo HDL & $13(5.5 \%)$ & $16(9.1 \%)$ & 0.91 & $29(29 \%)$ \\
\hline Hyper LDL & $14(6 \%)$ & $18(10.2 \%)$ & 0.45 & $32(32 \%)$ \\
\hline \multicolumn{5}{|l|}{ Family history diabetes } \\
\hline Family diabetes & $7(3 \%)$ & $5(2.8 \%)$ & 0.32 & $12(12 \%)$ \\
\hline Stroke & $1(0.4 \%)$ & $2(1.1 \%)$ & 0.4 & $3(3 \%)$ \\
\hline \multicolumn{5}{|c|}{ Diabetes treatment and glycemic balance } \\
\hline Metformin & $23(9.8 \%)$ & $42(23.9 \%)$ & 0.001 & $65(65 \%)$ \\
\hline Sulfamide & $8(3.4 \%)$ & $6(3.4 \%)$ & 0.32 & $14(14 \%)$ \\
\hline Insulin & $4(1.7 \%)$ & $5(2.8 \%)$ & 0.43 & $9(9 \%)$ \\
\hline Capillary blood glucose (mg/dl) & 178 & 189 & 0.02 & 183 \\
\hline Average glycated hemoglobin & 8.3 & 7.8 & & 7.99 \\
\hline
\end{tabular}




\subsection{Abnormalities at the ECG}

The abnormalities found at the ECG were summarized as follows:

Rhythm disorders were noted in $20 \%$ of patients, $13 \%$ of whom were women. Right atrial hypertrophy was found in $11 \%$ of patients and left hypertrophy in both men and women (25\%). Wolf-Parkinson White syndrome was present in $2 \%$ of patients. A complete right bundle block was present in $11 \%$ of patients. Primary repolarization disorders were noted in $17 \%$ of patients and secondary in $18 \%$ of patients, postero-diaphragmatic necrosis in $14 \%$ of patients, real posterior necrosis in $2 \%$ of patients, extensive anterior necrosis in $15 \%$ of patients. The QT interval was lengthened in $21 \%$ of patients including 14 women. Left ventricular hypertrophy was present in $33 \%$ of patients and right ventricular hypertrophy was found in $10 \%$ of patients. These anomalies are summarized in Table 2.

The bivariate analysis showed that electrocardiographic abnormalities were more correlated with the association of certain risk factors such as hypertension and dyslipidemia, the feminine gender, but also the poor glycemic balance. In addition, the physical activity and the treatment had a protective effect.

\section{Discussion}

A number of 100 patients consisted of 43 male and 57 female diabetics. The sex/male/female ratio was 0.7 . This prevalence was close to that one found by Gueye and al [4] in 2009 in a study made with a representative sample of the Dakar population on the prevalence of diabetes. She noted a female predominance (59\%).

Among our patients several abnormalities were detected at the ECG and most were correlated with the factors associated with diabetes.

Abnormalities were found in 20 (20\%) percent of patients, including 13 women, 6 were housewives $(\mathrm{p}=0.08)$. HTA and physical inactivity were present in $11 \%$, a low HDL-c in $14 \%$ of patients and $9 \%$ a high LDL-c. All patients who had an arrhythmia had an HbA1C greater than 7\% $(\mathrm{p}=0.001$, OR: $1.2(0.09-$ $12.3)$ ). Tachycardia was present in $28 \%$ of patients, including 16 women (16\%) and bradycardia in 7 patients (7\%). Hypertensive patients were 1.5 times more likely to have a rhythm disorder. Anastase et al. [5] who had conducted the same study in Cameroon found this predominance of arrhythmias in women with higher proportions: 31 patients $(15 \%)$ in men and 37 patients $(17.4 \%)$ in women $\mathrm{p}=0.5)$. HAD was found in $11 \%$ of patients and HAG in equal proportions in men and women $(25 \%)$, in $28 \%$ without profession, in $33 \%$ hypertensive ( $\mathrm{p}=$ 0.007 ), in $5 \%$ with diabetic cardiomyopathy.

Conduction disorders were found in $11 \%$ of patients, the study concluded at a $1^{\text {st }}$ degree BAV in 2 patients and a Wolf-Parkinson White syndrome in 2 patients. Women were twice as likely to have a short PR ( $\mathrm{p}=0.003, \mathrm{OR}: 1.3)$, which was also present in $6 \%$ hypertensive patients. A high LDL-c level was noted in $3 \%$ of patients and a low HDL-c in $2 \%$. The mean HbAlC was $8 \%$. The right 
Table 2. Electrocardiographic abnormalities detected.

\begin{tabular}{|c|c|}
\hline Anomaly ECG & Number of cases \\
\hline IRREGULAR RHYTHM & 20 \\
\hline NON-SINUSAL RHYTHM & 10 \\
\hline TACHYCARDY & 28 \\
\hline BRADYCARDY & 7 \\
\hline PR SHORT & 6 \\
\hline PR ELONGATE & 2 \\
\hline AXIS DEVIE A LEFT & 38 \\
\hline RIGHT AXIS RIGHT & 7 \\
\hline DURATION QRS ELONGATE & 5 \\
\hline PR SHORT & 6 \\
\hline PR ELONGATE & 2 \\
\hline BAV $1^{\mathrm{E}}$ DEGRE & 2 \\
\hline LEFT ATRIAL HYPERTROPHY & 50 \\
\hline RIGHT HYPERTROPHY ATRIAL & 11 \\
\hline Q-WAVE & 32 \\
\hline RIGHT BRANCH BLOCK & 11 \\
\hline ENDOCARDIAL UNDER LESION & 35 \\
\hline EPICARDIAL UNDER LÉSION & 9 \\
\hline TROUBLES OF REPOLARIZATION & 13 \\
\hline ISCHAEMIA UNDER EPICARDIAL & 20 \\
\hline ISCHAEMIA UNDER ENDOCARDIAL & 6 \\
\hline RIGHT VENTRICULAR HYPERTROPHY & 11 \\
\hline LEFT VENTRICULAR HYPERTROPHY & 33 \\
\hline QT ELONGATE & 4 \\
\hline HEMIBLOC ANTERIOR & 10 \\
\hline EXTRASYSTOL ATRIAL & 3 \\
\hline EXTRASYSTOL VENTRICULAR & 10 \\
\hline
\end{tabular}

branch block was found in $11 \%$ of patients, the anterior hemi block in $10 \%$. Anastase et al. [5] found an abnormal conduction in $11.9 \%$ of patients with a statistically significant difference in distributions between men and women $(\mathrm{p}=$ 0.003).

The study found primary troubles in 17 patients (17\%) and secondary disorders in 18 patients (18\%), a T-wave hyperkalaemia in 4 patients (4\%). 11 males and 17 females was more correlated with the female $(\mathrm{p}=0.04, \mathrm{OR}=0.9 \mathrm{IC})$, and was significantly correlated with the T-wave abnormality: $0.03-4.5$. In $9 \%$ of patients, $7 \%$ of patients with ischemic heart disease and $8 \%$ with hypertension $(\mathrm{p}=$ $0.03, \mathrm{OR}=2.02)$ had an epicardial lesion. These disorders were mainly corre- 
lated with poor glycemic control noted more in women $(\mathrm{p}=0.03, \mathrm{OR}=2.4)$. An endocardial lesion was found in $33 \%$ of patients, 13 of whom were men (13\%), 22 women $(\mathrm{p}=0.152)$ and $27 \%$ hypertensive $(\mathrm{p}=0.002, \mathrm{OR}=4.33)$. Anastase et al. [5] found the T-wave abnormality in 80 patients, that is to say $20.9 \%$, the presence of diabetic nephropathy significantly associated with $\mathrm{T}$-wave aberrations [OR: 0.45 (95\% CI: 0,24 to 0.83 )] and myocardial ischemia [OR: 0.47 (from 0.23 to 0.95 )]; Otherwise, as in our study, diabetes medications and disease control markers were not associated with outcomes.

Indeed, these $\mathrm{T}$ wave abnormalities are, in one hand, repolarization disorders related to left ventricular hypertrophy and/or hypertension as reported in some African studies [5] [6].

Matthew et al. [6] found a prevalence of abnormalities dominated by T-wave abnormalities (154 patients, that is to say 24.3\%). This high prevalence of T-wave abnormalities can be strong predictors of ischaemic heart disease as reported by several heights, however several studies report the physiological aspect in the black subject of the negative $\mathrm{T}$ wave.

The study found postoperative diaphragmatic necrosis in 14 patients, $14 \%$, real posterior necrosis in 2 patients, extensive anterior necrosis in 15 patients, that is to say $15 \%$, and anterior infarction on BBG with the sign of Cabrera. They were present in 21 hypertensive patients ( $p=0.03, \mathrm{OR}=1.16, \mathrm{IC}=0.093-14.5$ ). These data were more associated with poor glycemic control but also with the high prevalence of hypertension in these patients. This prevalence is similar to that one found in stroke patients in a South African study [7], and thus provides more evidence to support the high cardiovascular risk of patients with diabetes in our regions.

The QT interval was lengthened in $21 \%$ of patients, 14 of whom were women $(\mathrm{p}=0.6)$. It was more common in sedentary patients $(14 \%)$ and in $7 \%$ with nonproliferative diabetic retinopathy $(\mathrm{p}=0.027, \mathrm{OR}=1.3, \mathrm{IC}: 0.4-3.45) .(\mathrm{p}=0.04$, $\mathrm{OR}=1.03$, IC: $0.05-7.8), 11 \%$ with poor glycemic control $(\mathrm{p}=0.000)$, and $7 \%$ with a low HDL-c $(\mathrm{p}=0.000)$.

Left ventricular hypertrophy was present in our study in $33 \%$ of patients, $15 \%$ of whom were men and $18 \%$ of women $(\mathrm{p}=0.09)$. The majority $(57 \%)$ had more than 10 years of diabetes $(\mathrm{p}=0.03$ ), the risk was multiplied by 1.8 . In hypertensive patients $(71 \%)$, it was present in 25 patients, is $25 \%(\mathrm{p}=0.009, \mathrm{OR}=3.04)$. Right ventricular hypertrophy was found in $10 \%$ of patients, including $6 \%$ of men and $4 \%$ of women, in 5 patients with diabetes for more than 10 years, in 8 hypertensive patients, 7 in moderate activity (3\%) and mild (4\%) in 3 known dyslipidemic patients. Lutalle et al. [8], in a similar study in Tanzania found a prevalence of $16 \%$ of HVG in a study looking for this anomaly in diabetic patients. These high prevalences may be related to the high prevalence of hypertension in our studies $71 \%$ and $50.5 \%$ for Anastase et al. [6].

The strong relationship between hypertension and diabetes plays an important role in the development HVG and myocardial ischemia. Hypertension, ob- 
Table 3. Results of bivariate analyzes between risk factors and electrocardiographic abnormalities.

\begin{tabular}{|c|c|c|c|}
\hline Risk factors & $\mathbf{P}$ & Odds ratio & $\begin{array}{l}\text { Risk of having an } \\
\text { electrocardiographic abnormality }\end{array}$ \\
\hline Gender female & 0.006 & 1.5 & Increases \\
\hline Physical activity & 0.68 & & Not increases \\
\hline \multicolumn{4}{|c|}{ Personal background and terrain: } \\
\hline - HTA & 0.004 & 1.8 & Increases \\
\hline - Stroke & 0.57 & & Not increases \\
\hline - Diabetes & 0.003 & 1.3 & Increases \\
\hline - Dyslipidemia & 0.015 & 1.4 & Increases \\
\hline Obesity & 0.9 & & Not increases \\
\hline High blood pressure & 0.005 & 1.5 & Increases \\
\hline Diabetes & 0.004 & 1.8 & Increases \\
\hline Dyslipidemia & 0.022 & 1.5 & Increases \\
\hline Active smoking & 0.6 & & Not increases \\
\hline Passive smoking & 0.8 & & Not increases \\
\hline Old smoking & 0.44 & & Not increases \\
\hline Sedentary lifestyle & 0.54 & & Not increases \\
\hline HbA1c greater than $7 \%$ & 0.003 & 1.7 & increases \\
\hline Antidiabetic treatment & 0.8 & & Not increases \\
\hline
\end{tabular}

esity and dyslipidemia are reported to aggravate the prevalence of these abnormalities in type 2 diabetics, comparable to a study on the occurrence of HVG (Hense and Himero [9]). Electrocardiographic abnormalities were more correlated with the association of certain risk factors such as hypertension, dyslipidemia, feminine gender, but also poor glycemic control. In addition, physical activity and treatment by metformin and/or associated with insulin had a protective effect. These bivariate analysis data are shown in Table 3. The multivariate analysis of the different risk factors by logistic regression on the electrocardiographic abnormalities showed that 2 of these factors increased the risk of presenting anomalies: the female gender, hypertension. Good control of risk factors had a protective effect.

\section{Conclusions}

Electrocardiographic abnormalities are common in patients with diabetes but also relate to other associated risk factors. This makes it possible to better evaluate the impact of cardio-vascular risk on the heart but also to predict the occurrence of cardiovascular accidents in our context. The analysis of the electrocardiographic results in relation to the epidemiological data makes it possible to formulate some recommendations:

- Advocate for ECG availability in annual diabetic check up; 
- Support patients with ischemic heart disease, diabetic cardiomyopathy, or other abnormalities, by concentrating their treatment on the better monitoring and balance of associated cardiovascular risk factors;

- Increase the number of patients through a study with more sites and set up a coordinated system of follow-up and care of patients involving all the actors concerned.

\section{Conflitct of Interest}

The authors have nothing to disclose.

\section{References}

[1] Cosnay, P., Barthelemy, B., Marchal, C., et al. (2004) Heart and Diabetes. La Revue de Médecine Interne, 25, 334-336. https://doi.org/10.1016/j.revmed.2004.10.011

[2] Dunning, B.E. and Gerich, J.E. (2007) The Role of Alpha-Cell Dysregulation in Fasting and Postprandial Hyperglycemia in Type 2 Diabetes and Therapeutic Implications. Endocrine Reviews, 28, 253-283. https://doi.org/10.1210/er.2006-0026

[3] Diop, S.N., Wade, A., Lokrou, A., Diedhiou, D. and Adoueni, V.K. (2013) Management of Type 2 Diabetes in Routine Medical Practice in Sub-Saharan Africa: Results of the AMAR-AFO Study in Senegal and Côte d'Ivoire. Medicine of Metabolic Diseases, 7, 363-367.

[4] Gueye, L., Duboz, P., Chapuis-Lucciani, N. and Boëtsch, G. (2012) Prevalence of Diabetes and Associated Risk Factors in Senegalese Urban (Dakar) Population. Diabetes \& Metabolism, 38, 332-336. https://doi.org/10.1016/j.diabet.2012.02.011

[5] Anastase, D., Shukem, S., Adam, A., et al. (2012) Prevalence and Determinants of Electrocardiographic Abnormalities in Sub-Saharan African Individuals with Type 2 Diabetes. Cardiovascular Journal of Africa, 23.

[6] Matthew, B.S., Jasmin, D., Lingyi, L., Jianzhao, X., et al. (2014) Prevalence and Determinants of Electrocardiographic Abnormalities in African Americans with Type 2 Diabetes. Journal of Epidemiology and Global Health, 4, 289-296. https://doi.org/10.1016/j.jegh.2014.04.003

[7] Joubert, J., McLean, C.A., Reid, C.M., Davel, D., Pilloy, W., et al. (2000) Ischemic Heart Disease in South African Stroke Patients. Stroke, 31, 1294-1298. https://doi.org/10.1161/01.STR.31.6.1294

[8] Lutale, J.J., Thordarson, H., Gulam-Abbas, Z., Vetvik, K. and Gerdts, E. (2008) Prevalence and Covariates of Electrocardiographic Left Ventricular Hypertrophy in Diabetic Patients in Tanzania. Cardiovascular Journal of Africa, 19, 8-14.

[9] Hense, W.H., Gneiting, B. and Muscholl, M. (1998) The Association between Body Size and Body Composition with Left Ventricular Mass; Impact for Indexation in Adults. Journal of the American College of Cardiology, 32, 451-457.

https://doi.org/10.1016/S0735-1097(98)00240-X 
Submit or recommend next manuscript to SCIRP and we will provide best service for you:

Accepting pre-submission inquiries through Email, Facebook, LinkedIn, Twitter, etc. A wide selection of journals (inclusive of 9 subjects, more than 200 journals)

Providing 24-hour high-quality service

User-friendly online submission system

Fair and swift peer-review system

Efficient typesetting and proofreading procedure

Display of the result of downloads and visits, as well as the number of cited articles Maximum dissemination of your research work

Submit your manuscript at: http://papersubmission.scirp.org/

Or contact ojim@scirp.org 